\title{
Global IT and IT-enabled services
}

\author{
Michael Chau • George L. Ball • Jinghua Huang • \\ Jian Chen • J. Leon Zhao
}

Published online: 31 July 2010

(C) The Author(s) 2010. This article is published with open access at Springerlink.com

We are now experiencing globalization in virtually all areas of business and economics. Globalized information management has become an important and interesting area in both research and practice. The advances of the Internet and mobile networks have linked the world together and enabled corporations to take advantage of talents and services available around the globe. In view of this, we have organized a special issue of Information Systems Frontiers on this topic. This special issue titled Global IT and IT-Enabled Services is based on a selected set of papers presented in the IEEE Symposium on Advanced Management of Information for Globalized Enterprises (AMIGE'08) held in September 2008 in Tianjin, China. AMIGE'08 is part of the IEEE Congress on Services and is co-organized by China Association of Information Systems (CNAIS).

The objective of this special issue is to disseminate recent research results in the interdisciplinary study of globalized information management and to promote new ideas. Globalized information management is multidisciplinary and spans such fields as computer science,

\footnotetext{
M. Chau $(\bowtie)$

The University of Hong Kong,

Pokfulam, Hong Kong

e-mail: mchau@business.hku.hk

G. L. Ball

Raytheon Missile Systems,

Tucson, AZ, USA

J. Huang $\cdot$ J. Chen

Tsinghua University,

Beijing, China

J. L. Zhao

City University of Hong Kong,

Kowloon, Hong Kong
}

industrial engineering, information systems, management science and engineering, and operations management.

Research in global IT and IT-enabled services covers a wide spectrum of topics. These include business processes and management in a global setting, such as global workflow technologies and applications, global information system integration and interaction, globalized supply chain management, and global knowledge management.

Another area of research is related to the cultural differences occurring in the global business environment, such as global software development, outsourcing and offshoring strategies, IT governance and compliance across national boundaries, and privacy, assurance and trust in a global environment.

In addition, there is also research in the area of making use of latest information technologies and service computing to enhance organizations' competitive advantages in the global business environment. Topics of research in this area include service-oriented enterprises and architectures, service computing and service management, social computing, transformation of enterprise information systems, technology transfer and adoption, and Web 2.0 technologies and applications for globalized organizations.

Service is an old concept originated in the commercial world, which indicates an exchange of value from one party to another through some experiences in an area of need that might be related to the sale of a product. In recent years, service orientation has found its way in the field of information technologies, which has to do with how components in a computing system interact with one another. Service orientation advocates the enablement of service-oriented architecture that can sign on and off system components without interrupting existing information services (Zhao et al. 2007). The globalization of economic activities in the world has made service orientation increas- 
ingly more important because a globalized economy has no off time because the Internet and the world runs 24 times 7 .

There has been a surge in interest in services science in the developed economies and booming economies such as China and India. However, there is a real need for education about services science in business schools. We need to apply new research findings on achieving service excellence, service quality, customer satisfaction and retention, and service delivery. In the era of the Internet, there is also a great need to create a curriculum to address the emerging challenges of the global services. As such, the development of knowledge about global service systems in educational institutions will shape future of research and drive the development of interdisciplinary curricula (Bitner and Brown 2006). According to Bitner and Brown (2006), the study of services has a history in business schools that cuts across disciplines including management, marketing, operations, and human resources; however, the prevalence of published research in this area has come from services marketing, a field that emerged between 1970 and 1990.

In the field of services science, service is exchange of value between a service giver and a service receiver under a given service system, comprised of a configuration of resources such as people, information, and technology. Service science is the study of service systems and of the cocreation of value within complex configurations of resources. Vargo et al. (2008) argued that value is fundamentally derived and determined in use-the integration and application of resources in a specific context-rather than in exchangeembedded in firm output and captured by price. In their view, service systems interact through mutual service exchange relationships, improving the adaptability and survivability of all service systems engaged in exchange, by allowing integration of resources that are mutually beneficial.

Presently, there is a need to bridge the related fields of study in services including service computing and service management (Zhao et al. 2008). Service has different meanings in different fields. A service in service computing refers to a computational unit that has certain computational functionality and behavior, whereas in service management, a service means an offering of certain human attention and a delivery of certain meaningful results in terms of product or information. Further, the subject of service administration is different in service computing and service management. Service administration in service computing generally concerns a piece of software; in contrast, service administration in service management concerns a person or an organizational unit. It is clear that service computing mainly deals with service relationships involving software components; on the other hand, service management mainly deals with service relationships involving people. Naturally, there is a relationship between service computing and service management since they both involve people and software. This unification can also make knowledge sharing across disciplinary boundaries easier since it might be possible to share certain principles between service computing and service management.

An 18-month effort by Arizona State University's Center for Services Leadership identified a set of global, interdisciplinary research priorities focused on the science of service. The research process with worldwide corporate and academic participation led to the identification of 10 overarching research priorities (Ostrom et al. 2010): (1) Fostering service infusion and growth, (2) Improving wellbeing through transformative service, (3) Creating and maintaining a service culture, (4) Stimulating service innovation, (5) Enhancing service design, (6) Optimizing service networks and value chains, (7) Effectively branding and selling services, (8) Enhancing the service experience through cocreation, (9) Measuring and optimizing the value of service, and (10) Leveraging technology to advance service. Under each priority, more specific topics are also identified by the researchers. The goal of this research is to spur more research on service systems in a networked business world in order to enhance our understanding of services and create new knowledge on today's most important opportunities and challenges.

This special issue has a particular focus on service computing and management as an enabler to global operations through business process automation. Seven papers were chosen for this special issue for their relevance to global IT and IT-enabled services. The first three papers in the special issue investigate the topic of business processes and IT-enabled services in the global business environment. The paper by $\mathrm{Hu}$ (2010) looks at enabling trustworthy and secure provision of services and service composition across enterprise boundaries. This paper reviews the importance of business process modeling technologies and security requirements in order to derive a trust federation from formally described business process models. This approach has been demonstrated to be applicable and feasible in support of trust management in service-centered application environments.

Reporting systems are often separated from online transaction processing systems (OLTP). Technological advances require that this separation be re-evaluated in light of new trends for data storage management. Bog et al. (2010) designed a new benchmark combining transaction processing and operational reporting. Such systems offer up-to-date information and the flexibility of the entire data set for reporting.

Site selection is one of the most critical issues among the rapid growth of service-based economics activities since the last decade. Wu et al. (2010) proposed a joint learning scheme to quantify the interrelationships between the 
business performances of the service sites and their nearby business environment. This scheme employs both the Probabilistic Latent Semantic Analysis (PLSA) on Geographical Information Systems (GIS) data and the clustering on the service performance data. Bank branch selection is used as a case study to illustrate the merit of this scheme.

It has become increasingly important for organizations to share and reuse their valuable information to gain sustainable competitive advantages in the rapidly changing business environment. The second set of three papers in this issue is devoted to this area. Panchenko et al. (2010) pointed out that it is important to quickly gain deep and detailed insights over a large amount of either internally developed or foreign source code. The three major requirements for a source code repository are the ability to handle a large amount of data, fine granularity, and high speed. Existing solutions are currently unable to fulfill all three requirements. This paper provides a technical basis of a global repository for structural data management that satisfies these requirements. The authors propose a data model that stores fine-grained structural information in a compact way and enables flexible and expeditious querying. Graph indexing enables the proposed data model to expeditiously answer fine-grained structural queries. Based on this data model, an approach has been proposed to support future development activities.

It is difficult to support the reuse of existing source code because of the insufficient semantic knowledge on code functionality in the context of business processes. The paper by Ilk et al. (2010) presents an automated approach to enrich source code components with business semantics. They introduce "Semantic Enrichment Process" to support code reuse for service-oriented architectures-based development during system modernization efforts. The approach is evaluated in the framework of a commercial enterprise system application. Initial results indicate that the proposed approach is useful for annotating source code components with business specific knowledge.

The paper by Li et al. (2010) applies process mining to analyze the knowledge maintenance logs as part of process discovery. Since knowledge is an essential strategic resource for an organization, quality is very important in determining the effect of reuse and sharing. As such, knowledge to be reused should be checked in advance through a knowledge maintenance process. However, in organizations, the actual knowledge maintenance processes and the processes perceived by the management are not fully identical. The authors of this paper propose an optimization strategy based on the actual process model, which is more objective and adaptive for the real knowledge maintenance needs. Experimental results have shown the usefulness and effectiveness of the proposed methods.
The last paper, written by Nan Zhang, Xunhua Guo, and Guoqing Chen (in press), concludes the special issue by analyzing the phenomenon that IT/IS user acceptance declines after the initial period from a cultural perspective in China. In order to understand what changes have taken place in users' perception from the initial period of usage to the period of acceptance decline, the paper focuses on the behavioral factors that influence the adoption of new technology and systems over a longitudinal period. Based on an extended model derived from the Technology Acceptance Model (TAM), two empirical cases on English learning software and the e-Government system are presented to analyze users' adoption behavior toward the systems.

We wish to express our appreciation to Professor R. Ramesh and Professor H. Raghav Rao, the editors-in-chief of ISF, for making this special issue possible. We also thank the authors, reviewers, and all other people involved in the preparation of this special issue. Special thanks go to Alice Lee of the University of Hong Kong for her help in editorial work. We hope that the collection of papers presented here will stimulate further research in the areas related to the global IT and IT-Enabled services.

Open Access This article is distributed under the terms of the Creative Commons Attribution Noncommercial License which permits any noncommercial use, distribution, and reproduction in any medium, provided the original author(s) and source are credited.

\section{References}

Bitner, M. J., \& Brown, S. W. (2006). The evolution and discovery of services science in business schools. Communications of the $A C M, 49(7), 73-78$.

Bog, A., Plattner, H., \& Zeier, A. (2010). A mixed transaction processing and operational reporting benchmark. Information Systems Frontiers.

$\mathrm{Hu}$, J. (2010). Automating trust management for cross-organizational business processes. Information Systems Frontiers.

Ilk, N., Zhao, J. L., Goes, P., \& Hofmann, P. (2010). Semantic enrichment process: an approach to software component reuse in modernizing enterprise systems. Information Systems Frontiers.

Li, M., Liu, L., \& Yin, L. (2010). A process mining based approach to knowledge maintenance. Information Systems Frontiers.

Ostrom, A. L., Bitner, M. J., Brown, S. W., Burkhard, K. A., Goul, M., Smith-Daniels, V., et al. (2010). Moving forward and making a difference: research priorities for the science of service. Journal of Service Research, 13, 4-36.

Panchenko, O., Plattner, H., \& Zeier, A. (2010). Efficient storing and fast querying of source code. Information Systems Frontiers.

Vargo, S. L., Maglio, P. P., \& Akaka, M. A. (2008). On value and value co-creation: a service systems and service logic perspective. European Management Journal, 26(3), 145-152.

Wu, J., Chen, J., Wang, H., \& Ren, Y. (2010). GIS enabled service site selection: environmental analysis and beyond. Information Systems Frontiers. 
Zhang, N., Guo, X., \& Chen, G. (in press). Why adoptation and use behavior of IT/IS cannot last? Two studies in China. Information Systems Frontiers.

Zhao, J. L., Hsu, C., Jain, H. K., Spohrer, J. C., Tanniru, M., \& Wang, H. J. (2008). ICIS 2007 Panel report: bridging service computing and service management: how MIS contributes to service orientation. Communications of the Association for Information Systems, 22, 413-428. Article 22.

Zhao, J. L., Tanniru, M., \& Zhang, L.-J. (2007). Services computing as the foundation of enterprise agility: overview of recent advances and introduction to the special issue. Information Systems Frontiers, 9(1), 1-8.

Michael Chau received the Bachelor's degree in computer science and information systems from the University of Hong Kong in1998, and the $\mathrm{Ph} . \mathrm{D}$. degree in management information systems from the University of Arizona, Tucson, USA in 2003. He is currently an Assistant Professor in the School of Business at the University of Hong Kong. His current research interests include information retrieval, Web mining, data mining, knowledge management, electronic commerce, and security informatics. He has published more than 70 research articles in leading journals and conferences, including ACM Transactions on Information Systems, Communications of the ACM, Decision Support Systems, IEEE Computer, Journal of the America Society for Information Science and Technology, and Journal of the Association for Information Systems. He is a member of IEEE, ACM, ASIST, and AIS and is the chairman of the Computational Intelligence Chapter of the IEEE (HK). He is the organizing chair or program chair of five conferences/workshops and the organizing committee or program committee member of more than 40 international conferences. More information can be found at http://www. business.hku.hk/ mchau/.

George Ball is a Raytheon Fellow and has over 20 years of experience in the development of computer technology to investigate problems in the biological and physical sciences. His current position is the development of External Relationships and R\&D for the Advanced Information Technology Directorate of Missile Systems IT. In this capacity, he develops collaborations with academic institutions to find partnership opportunities and to shape the educational curricula of future Raytheon employees. George also oversees R\&D efforts with university and industrial labs that leverage next generation concepts in information technology. He has published over 50 papers in leading journals and conferences including IEEE Computational Science and Engineering, AI Applications, Communications of the ACM, and Ecological Modeling. George has BS and MS Degrees in Ecology and Evolutionary Biology and a doctorate in Natural Resources from the University of Arizona.

Jinghua Huang is Professor and Deputy Chair of Department of Management Science and Engineering, School of Economics and Management, Tsinghua University. She received her Ph.D. in Information Systems from Tsinghua University. She has conducted research at Sloan School of MIT, UBC and University of Waterloo as a visiting scholar. In 1997, she spent a year at the University of Illinois as a Fulbright Scholar. Her main research interests include electronic business, decision support systems, and information systems analysis. Her papers have appeared in Information \& Management, Communications of AIS, Computers \& Industrial Engineering, IEEE International Conference on Systems, Man and Cybernetics, IEEE International Conference on Web Intelligence, World Multiconference on Systemics, Cybernetics and Informatics. She is the author of nine books in Chinese.
Jian Chen received the B.Sc. degree in Electrical Engineering from Tsinghua University, Beijing, China, in 1983, and the M.Sc. and the $\mathrm{Ph} . \mathrm{D}$. degree both in Systems Engineering from the same University in 1986 and 1989, respectively. He is EMC Professor and Chairman of Management Science Department, Director of Research Center for Contemporary Management, Tsinghua University. His main research interests include supply chain management, E-commerce, decision support systems. Dr. Chen has published over 150 papers in refereed journals and has been a principal investigator for over 30 grants or research contracts with National Science Foundation of China, governmental organizations and companies. He has been invited to present several plenary lectures. He is the recipient of Ministry of Education Changjiang Scholars, Fudan Management Excellence Award, IBM Faculty Award, Science and Technology Progress Awards of Beijing Municipal Government; the Outstanding Contribution Award of IEEE Systems, Man and Cybernetics Society; Science and Technology Progress Award of the State Educational Commission; Science \& Technology Award for Chinese Youth. He has also been elected to IEEE Fellow. He is the editor of Journal of Systems Science and Systems Engineering, an area editor of Electronic Commerce Research and Applications, an associate editor of IEEE Transactions on Systems, Man and Cybernetics: Part A, IEEE Transactions on Systems, Man and Cybernetics: Part C, and Asia Pacific Journal of Operational Research and serves on the Editorial Board of International Journal of Electronic Business, International Journal of Information Technology and Decision Making and Systems Research and Behavioral Science.

J. Leon Zhao is currently Head and Chair Professor in Information Systems, City University of Hong Kong. He was Eller Professor and Interim Head in the Department of Management Information Systems, University of Arizona before January 2009. He also taught previously at HKUST and College of William and Mary, respectively. He holds Ph.D. and M.S. degrees from the Haas School of Business, UC Berkeley, M.S. degree from UC Davis, and B.S. degree from Beijing Institute of Agricultural Mechanization. His research is on information technology and management, with a particular focus on workflow technology and applications in knowledge distribution, e-learning, supply chain management, organizational performance management, and services computing. Leon's research has been supported by NSF, SAP, and other sponsors. He received an IBM Faculty Award in 2005 for his work in business process management and services computing and was awarded National "Chang Jiang Scholars" Chair Professorship, Tsinghua University, China, 2009. Leon has been associate editor of Information Systems Research, ACM Transactions on MIS, IEEE Transactions on Services Computing, Decision Support Systems, Electronic Commerce Research and Applications, International Journal of Business Process Integration and Management, International Journal of Web and Grid Services, and International Journal of Web Services Research and is on the editorial board of Journal of Database Management. He has co-edited nine special issues in various IS journals. Leon has been chair or program chair for numerous conferences including the 5th International Conference on Design Science Research in Information Systems and Technology (DESRIST'10), the IEEE International Conference on Services Computing, Bangalore, India (SCC'09), the 2008 IEEE Symposium on Advanced Management of Information for Globalized Enterprises (AMIGE'08), the 2008 Arizona Exposium on Frontiers of Information Technology and Applications (FITA'08), the 2007 China Summer Workshop on Information Management (CSWIM'07), the 2006 IEEE Conference on Services Computing (SCC'06), the 2005 Workshop on Information Technology and Systems (WITS'05), and the 2003, Workshop on E-Business (WEB'03) among others. He has also served on many program committees in international conferences. 